\title{
Présentation de la journée du 11 février 2011
}

\section{Yves Le Berre}

\section{(2) OpenEdition}

\section{Journals}

Édition électronique

URL : https://journals.openedition.org//bl/1782

DOI : $10.4000 / \mathrm{lbl} .1782$

ISSN : 2727-9383

\section{Éditeur}

Université de Bretagne Occidentale - UBO

\section{Édition imprimée}

Date de publication : 1 février 2013

Pagination : 125-126

ISBN : 979-10-92331-00-4

ISSN : 1270-2412

\section{Référence électronique}

Yves Le Berre, «Présentation de la journée du 11 février 2011 », La Bretagne Linguistique [En ligne], 17 2013, mis en ligne le 01 mai 2021, consulté le 22 mai 2021. URL : http://journals.openedition.org/lbl/ 1782 ; DOI : https://doi.org/10.4000/lbl.1782

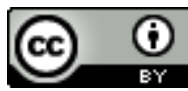

La Bretagne Linguistique est mise à disposition selon les termes de la Licence Creative Commons Attribution 4.0 International. 


\section{Présentation de la journée du 11 février 2011}

\section{$\mathrm{E}$}

n organisant cette journée d'étude thématique - formule exceptionnelle dans la vie du GRELB - consacrée à la rhétorique, nous souhaitons proposer aux chercheurs une entrée jusqu'à présent peu fréquentée dans l'univers des textes bretons.

Depuis le dictionnaire de dom Louis Le Pelletier, publié en 1752 , la littérature écrite et orale du breton a en effet été attentivement et savamment étudiée pour tout autre chose qu'elle-même. Par les celtomanes d'abord comme ultime trace tangible de la langue originelle de l'humanité, étroitement liée à l'hébreu. Puis par les romantiques comme ultime expression du gaulois, témoin des origines de la nation française. Plus récemment par les philologues comme conservatoire d'archaïsmes du brittonique introduit en Armorique par les immigrants du haut moyen âge. Concomitamment par les érudits locaux comme ensemble de documents susceptibles d'éclairer tel point de l'histoire régionale à des époques où les témoignages sont rares ou font défaut.

Toutefois quelque thème qu'ils abordent et quels que soient leurs qualités et leurs défauts, ces textes ont été écrits par des hommes qui espéraient transmettre à la postérité ou partager avec leurs contemporains des convictions, des émotions, du savoir. Nombre d'entre eux avaient une motivation spirituelle, quantité d'autres ont été longuement travaillés par la tradition orale. Leurs auteurs sont le plus souvent pénétrés du souci de présenter le contenu de sens sous une forme à la fois capable de susciter l'admiration des lecteurs ou des auditeurs et d'inscrire l'ensemble forme-contenu dans les canons du goût dominant à l'époque et dans le milieu social de leur composition. Ce ne sont donc pas de simples concrétions jaillies spontanément de la langue bretonne, mais de véritables actes de communication. C'est-à-dire des œuvres. 
Enseignée dans les séminaires aux futurs prédicateurs, dans les collèges aux futurs juges et avocats, la rhétorique formait un code social raisonné, fondé sur l'imitation des grands auteurs de l'antiquité, du moyen âge et de l'époque moderne. Les figures, ou tropes, donnaient le moyen d'orner leurs discours à des jeunes gens dont la position sociale reposerait bientôt sur l'usage public de la parole. Dans une société longtemps plongée dans une oralité laissant peu de place à l'écrit, l'apprentissage de la rhétorique leur permettait de devenir aux yeux de ceux qui leur étaient soumis des maîtres de la langue, donc des représentants légitimes des divers pouvoirs. Loin d'avoir disparu depuis l'acculturation générale à la lecture-écriture, la rhétorique a simplement pris d'autres formes : elle reste pour les politiques, les journalistes, les enseignants et les écrivains la méthode grâce à laquelle la parole spontanée devient discours social.

Le « décodage » des procédés d'écriture utilisés par les divers auteurs dont nous examinerons les œuvres nous permettra, du moins l'espérons-nous, de mieux saisir leur intentions, les relations qu'ils ont entretenues avec leurs lecteurs ou leurs auditeurs. Finalement de mieux comprendre ce qu'écrire en breton a pu signifier au cours du temps.

Yves LE BERRE pour le GRELB 